\section{Clinical \&}

\section{Scientific letters}

Letters not directly related to articles published in Clinical Medicine and presenting unpublished original data should be submitted for publication in this section. Clinical and scientific letters should not exceed 500 words and may include one table and up to

High prevalence of obesity qualifying for bariatric surgery in diabetics attending a hospital clinic

Funding for bariatric surgery throughout the UK is limited to named patients who fulfil National Institute for Health and Clinical Excellence (NICE) criteria. ${ }^{1}$ As described in a recent review on surgery for obesity this approach would disadvantage a large number who qualify but are denied surgery on the basis of what appears to be an arbitrary limitation of numbers. This is particularly so as several studies indicate that diet and medication are of limited value in long-term weight reduction. ${ }^{2,3}$ Conversely, there is evidence that planned five references. surgery in an appropriate setting is effective in maintaining weight reduction, reversing comorbidities and reducing mortality. ${ }^{4,5}$ Increasing funding for bariatric surgery in high-risk subjects eg diabetics, should be a high priority for planners and service providers because of the high prevalence of obesity.

One hundred and seventy-seven consecutive diabetics (116 males and 61 females; 37 with type 1 diabetes (T1DM) and 140 with type 2 diabetes (T2DM)) attended clinics to establish the prevalence of obesity that qualified for surgery. In both groups $63 \%$ had a body mass index $(\mathrm{BMI})>30 \mathrm{~kg} / \mathrm{m}^{2}$. However, eight T1DM $(21 \%)$ and 42 T2DM (30\%) ie $35.7 \%$ of all diabetics attending the clinics, had a BMI $>35 \mathrm{~kg} / \mathrm{m}^{2}$ and therefore were eligible for referral for bariatric surgery (BMI $>40$ in $21(11.9 \%$ - obesity type III); BMI $>50$ in two $(1.1 \%$ - super obesity)). There were four patients $(2.2 \%)$ on weight-reducing medication and only $1 \%$ had been referred for surgery. There was a significant correlation between BMI and waist circumference (WC) $\quad(r=0.8$; $\mathrm{p}=<0.001$ ) (Fig 1) but no significant difference in HbAlc, total and high-density lipoprotein cholesterol between increasing grades of obesity.

This study confirms a high prevalence of obesity in diabetics, of whom a signif- icant number would qualify for consideration of surgery according to current NICE guidelines. A positive relationship between BMI and WC was also demonstrated. Unfortunately, funding is limited to 14 patients per year in the studied region. Therefore a large number of diabetics even from this limited sample would not be considered for surgery. All who qualify on the basis of a raised BMI may not be suitable for surgery (because of comorbidities or a personal preference) but many more than currently allowed would certainly need to be considered. The availability of bariatric surgery and metabolic and nutritional services for obesity in high-risk groups, such as diabetes, should be increased in view of its proven efficacy and the lack of effective long-term alternatives. Physician and patient expectations would then be satisfied.

MA ADLAN
Consultant physician

A DRODGE

Specialist registrar in diabetes and endocrinology

\section{LDKE PREMAWARDHANA}

Consultant physician

Section of Diabetes and Endocrinology Department of Medicine Caerphilly Miners' Hospital Caerphilly, Wales

\section{References}

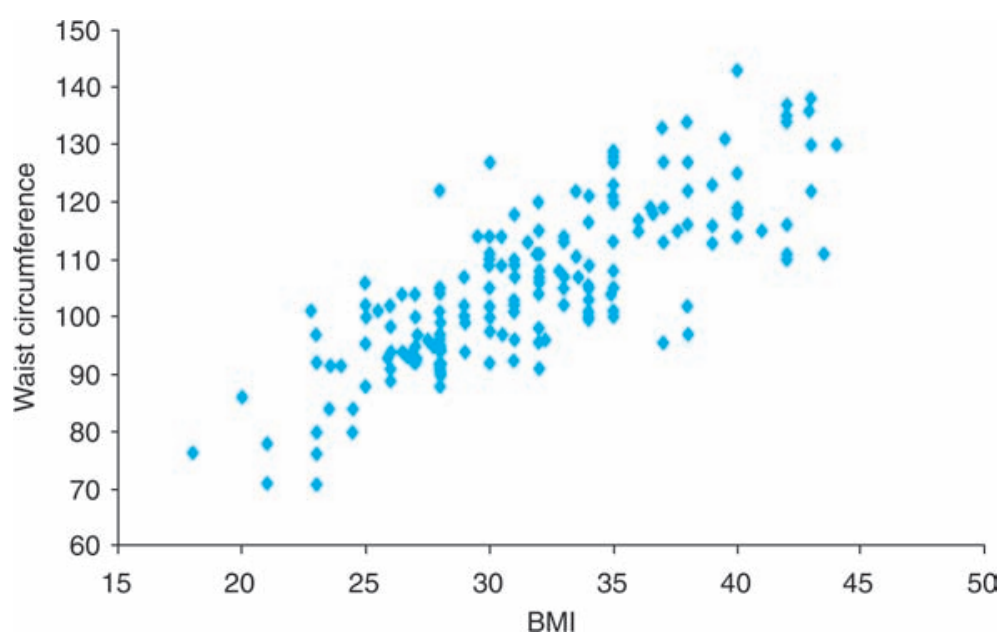

Fig 1. Waist circumference and body mass index (BMI) in 177 diabetics attending a hospital clinic $(r=0.8 ; p=<0.001)$.
1 National Institute for Health and tion, identification, assessment and management of overweight and obesity in adults and children. London: NICE, 2006.

2 Mark AL. Dietary therapy for obesity: an emperor with no clothes. Hypertension 2008;51:1426-34.

3 Rucker D, Padwal R, Li SK, Curioni C, Lau DC. Long term pharmacotherapy for obesity and overweight: Updated metaanalysis. BMJ 2007;335:1194-9.

4 Colquitt JL, Picot J, Loveman E, Clegg AJ. Surgery for obesity. Cochrane Database Syst Rev 2009;2:CD003641.

5 Adams TD, Gress RE, Smith SC et al. Long-term mortality after gastric bypass surgery. $N$ Engl J Med 2007;357:753-61. Clinical Exscellence. Obesity: the preven- 